\title{
Restructuring Urban Public Transport in India
}

\author{
Kaushik Deb, Tata Energy Institute, India
}

\begin{abstract}
Transportation in the urban context assumes great economic significance, as the productive efficiency of urban areas will be maintained only if mobility requirements in the cities are fully met. However, this productive efficiency is now threatened by the increasing number of vehicles causing congestion, and thus slower speeds on roads. An effective way to address this problem is to encourage greater use of public transport instead of personal vehicles. This requires both an increase in the carrying capacity of the public transport system and a quantum improvement in the quality of public transport.

In addition, despite the high volumes of traffic, most urban centers in India do not have any rail transit system to cater to intracity movements. Hence, there would be substantial dependence on bus services to meet public transport needs for the next several years. This is likely to result in a major restructuring of the current provisioning of public transport in the urban centers. This article highlights various options for restructuring the provision of road-based public transport and synthesizes them into a strategy for reform, given the commercial viability of the various activities carried out by public transport operators in India.
\end{abstract}

\section{Introduction}

Transport plays a significant role in the overall development of a nation's economy, particularly in the urban context, where cities are considered vertices of economic 
growth. However, concerns are being voiced about the sustainability of development in the transport sector as this sector accounts for a substantial and growing proportion of air pollution in cities. The most effective strategy for ensuring the sustainability of the urban transport sector is to check the decline in the share of public transport. This article outlines issues and concerns in the public transport sector and the need for reforms. It also suggests a reform strategy for the sector.

\section{Transport Sector in India}

India has witnessed rapid growth in the number of total vehicles registered in the last two decades. As of March 31, 1998, there were 41 million registered vehicles in the nation (Table 1).

\section{Table 1. Growth of Vehicles in India}

\begin{tabular}{ccccccc} 
Year & $\begin{array}{c}\text { No. of } \\
\text { Vehicles }\end{array}$ & $\begin{array}{c}\text { Two } \\
\text { Wheelers (\%) }\end{array}$ & $\begin{array}{c}\text { Car, Jeep, \& } \\
\text { Taxi (\%) }\end{array}$ & $\begin{array}{c}\text { Buses } \\
(\%)\end{array}$ & $\begin{array}{c}\text { Good } \\
\text { Vehicles (\%) }\end{array}$ & $\begin{array}{c}\text { Others } \\
\text { (\%) }\end{array}$ \\
\hline 1951 & 306 & 8.82 & 51.96 & 11.11 & 26.80 & 1.31 \\
1961 & 665 & 13.23 & 46.62 & 8.57 & 25.26 & 6.32 \\
1971 & 1,865 & 30.88 & 36.57 & 5.04 & 18.39 & 9.12 \\
1981 & 5,391 & 48.56 & 21.52 & 3.01 & 10.28 & 16.64 \\
1986 & 10.577 & 59.04 & 16.83 & 2.15 & 8.16 & 13.82 \\
1991 & 21,374 & 66.44 & 13.82 & 1.55 & 6.34 & 11.85 \\
1996 & 33,783 & 68.83 & 12.44 & 1.33 & 6.01 & 11.39 \\
1997 & 37,231 & 69.01 & 12.52 & 1.31 & 6.07 & 11.09 \\
1998 & 40,939 & 69.23 & 12.35 & 1.31 & 6.18 & 10.94
\end{tabular}

Source: MoST, 2000.

Along with the rise in vehicle population, the increased mobility demand is reflected in rising usage rates of personal vehicles. The problem has been accentuated by the gradual reduction of public transport in India as reflected in the declining share of buses in the total vehicle fleet in the country (a decline from more than $11 \%$ in 1951 to just over $1 \%$ in 1998).

The rapid increase in the number of motor vehicles in India calls for urgent measures to deal with the resultant congestion and pollution. In particular, encouraging greater use of public transport instead of personal vehicles, thereby slowing the trend toward increasing use of personal vehicles, is key. However, unless the quality of public transport services improves substantially, the trend of increasing 
preference for personal vehicles will continue. This calls for a complete change in the mindset of the operators. It is extremely important that the provision of public transport services be restructured to ensure service delivery that matches consumers' expectations. One way to do this is to organize the private sector to more effectively provide useful services. Improving the quality of services from public transport would also require restructuring of the State Road Transport Corporations [or State Road Transport Undertakings (SRTUs)] so that policy, planning, and regulatory functions are carried out by an entity other than the one involved in direct operations. There would also be a need for a regulatory framework to oversee all modes of public transport particularly, urban and suburban railways.

\section{Performance of Public Transport in India}

Public transport in India can be classified into two modes: rail and road. Out of the country's total passenger movement, 80 percent is met by road transport while the remaining 20 percent is carried by railways.

\section{Road Transport}

Road transport in India is operated by both the public and private sectors-comprising about 28.7 percent and 71.3 percent, respectively, of the total bus system. Government participation in road transport commenced in 1950, and since then SRTUs have been formed in every state.

As of March 1999, there were about 67 SRTUs in the country operating a fleet of more than 115,000 buses and employing about a quarter of a million people. Out of 59 corporations, 14 operate exclusively in the urban areas and the remaining 45 in mofussil' areas (including 9 corporations operating in hilly regions) (Table 2 ). Further, of the corporations operating in mofussil areas, about 8 operate only in rural areas (including the hilly regions); the remaining corporations operate in both rural and urban areas. Of the total number of buses held by corporations, 17,455 render services in urban areas; the remaining 95,310 vehicles operate in mofussil areas (including 2,659 in hilly regions) (ASRTU 2000).

Table 2. State Road Transport Undertakings in India

\begin{tabular}{lrrr} 
Number & Rural & Urban & Rural \& Urban \\
\hline SRTUs & 8 & 14 & 37 \\
Buses & 115,424 & 17,455 &
\end{tabular}

Source: ASRTU, 2000. 
The organizational form for public sector bus transportation varies from state to state, with the most common being a corporation constituted under the provisions of the Road Transport Corporation Act of 1950. There are 22 such corporations. In addition, 26 undertakings have been formed under the Indian Companies Act of 1956, while public transport is also operated by 11 municipal councils under various municipal legislations. Eight undertakings function as part of government departments (Figure 1).

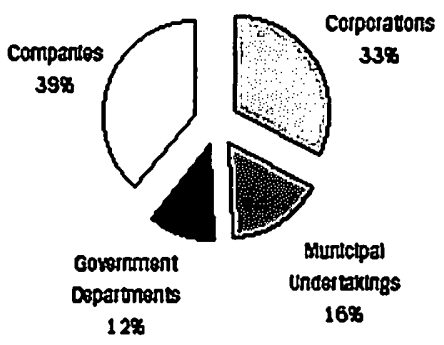

Figure 1. Management of SRTU's in India Source: ASRTU, 2000.

Public bus transport in India is provided through a multiplicity of mechanisms. These include:

- Own services: Under this mechanism, the SRTU uses its own fleet.

- Kilometer scheme: Private buses are hired to run services as required by the SRTU.

- Direct permits: Permits from the State Transport Authority (STA) are given directly to private operators to operate on specified routes. The buses are owned and operated by the private permit holder who also collects the fares. Fares and routes are as allowed by the STA under the Motor Vehicles Act of 1988. The private entities operate under the conditions of the permit granted to them. These operators have no relationship to the SRTU and operate on their own.

\section{Operational Performance}

The total strength of the urban SRTUs grew from just about 10,000 in 1991 to about 13,500 in 1999, an increase of 28 percent. However, while the total vehicle fleet strength grew at almost 10 percent per year in the 1990s (Table 1), the urban SRTU fleet grew by less than 3 percent per year (Figure 2). Given that the increase in the bus fleet during this period has also not been spectacular (Table 1), the size and spread of public transport has seen a decline in the last five years.

The operational characteristics, on the other hand, do not show any distinctive trend (Figure 3 ). While the kilometers operated daily by each bus have shown a steady increase, the proportion of the total fleet on road has been declining. 


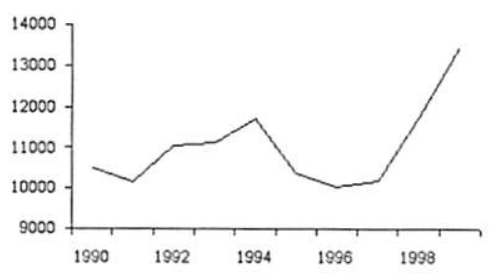

Figure 2. Growth in fleet strengths of SRTU's in urban India Source: ASRTU, 2000.

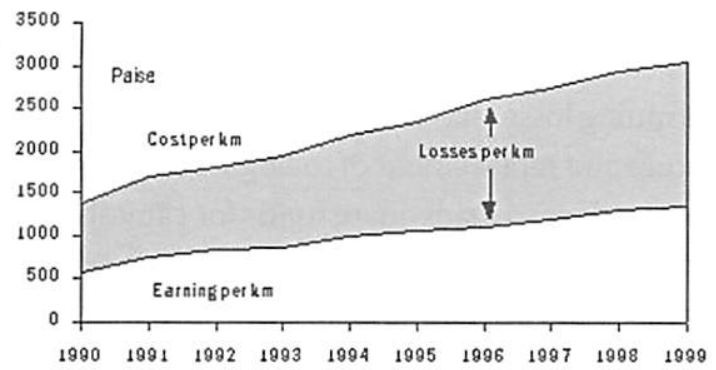

Figure 3. Financial performance (Rupees per kilometer) of SRTU's. Source: ASRTU, 2000.

\section{Financial Performance}

The overall financial performance of urban SRTUs in India appears to be gloomy, with the SRTUs headed toward a severe financial crisis in the very near future. As of March 1999 these corporations had incurred an accumulated loss of about 13 billion rupees-nearly as large as the aggregate amount of equity of both the union government and the state governments and reserves ( 14.60 billion rupees). Further, this debt is larger than the total assets of the SRTUs.

As earnings per kilometer have grown more slowly than costs per kilometer, losses per kilometer have grown by nearly 7 percent per year (Figure 4). This situation has developed because of continuing inefficiency in operations, uneconomical operations to meet the universal service obligation, and universal subsidization of 


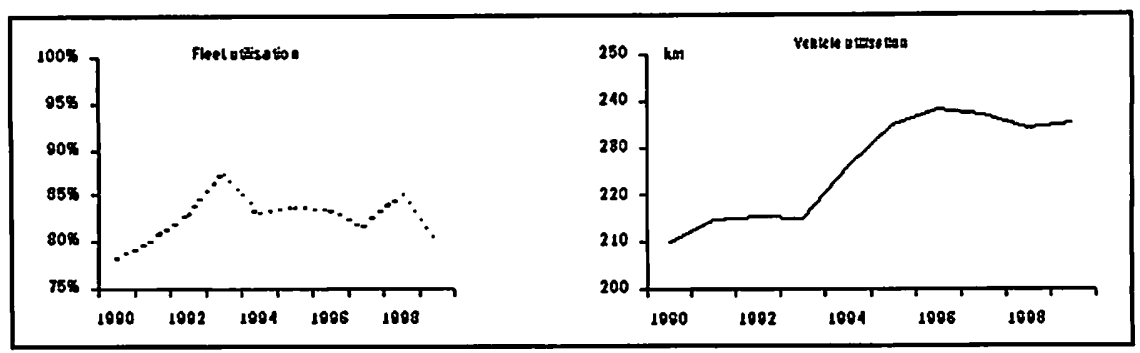

Figure 4. Operational performance of SRTU's in urban India. Source: ASRTU, 2000.

services. In addition, the motor vehicle taxation regime taxes buses more than personal vehicles, resulting in higher cost of operation for public transport.

A result of the continuing losses has been the inability to generate adequate funds for capital expenditure and replacement of rolling stock. There exists a vicious circle of continuous losses leading to inadequate funds for capital expenditure and poor management of the fleet, which in turn leads to poor operational performance, causing even higher losses. The mounting losses imply a substantial commitment from the government for the provision of public transportation services in urban India. The following sections review current operations and identify areas for reform.

\section{Rationale for Restructuring}

Improved transport systems are essential for accelerated economic growth. Transportation in the urban context assumes even greater significance. Large agglomerations are seen as the vertices of continued economic growth. The productive efficiency of urban agglomerations will be maintained only if mobility requirements in the cities are fully met. However, this productive efficiency in urban India is now threatened by the increasing number of vehicles, causing congestion and thus slower speeds on roads. Transportation infrastructure could be the primary bottleneck for the unimpeded growth of the state. Thus, it is important that the existing transportation infrastructure is utilized optimally. This requires meeting mobility needs efficiently through a greater modal share of public transport.

Another major consideration for restructuring public transport is the continued drain on the exchequer. With greater emphasis on fiscal discipline, it is becoming increasingly difficult for governments to continue funding such loss-making 
ventures. In addition, the role of the state in provisioning services that can be more efficiently provided by private operators is being questioned in a variety of fora.

\section{Augmenting Public Transport}

While it is recognized that the share of public transport in India is considerably higher than that in most developed countries, the cause for concern is the declining share. Among the major reasons for this decline are the inability of public transport operators to keep pace with the increasing demand and the deteriorating quality of service arising from continued losses and thus inadequate capital generation for capacity augmentation. This issue is dealt with in detail in the next section.

Another problem is the relatively little concern for consumer satisfaction. In most cities, government-owned agencies operate and manage public transport services. Given the virtual monopoly that public sector service providers enjoy, service planning has been largely dominated by operating convenience rather than by consumer convenience. With fares and tariffs not linked to costs of operation, there is little incentive for service providers to improve efficiency. Also, being public sector concerns, the emphasis on commercial orientation is limited. As a result, ridership changes and costs of operation are not concerns of the management. Thus, a change in the incentive regime is necessary to ensure attention to consumer satisfaction. This requires regulatory reforms and institutional restructuring in the urban public transport sector. It means splitting up monolithic public entities and allowing public sector suppliers to offer services in areas where they are better equipped to provide them.

\section{Mounting Losses of SRTUS}

The considerations for restructuring SRTUs also stem from mounting losses and poor operational performances, resulting in a continuous drain on scarce budgetary resources. A number of SRTU activities can be efficiently provided by the private sector. Also, private sector funds could be tapped to generate revenues for fleet augmentation and replacement.

In the postliberalization era, it would be difficult for governments to continue to provide financial support to such loss-making ventures, especially with the growing emphasis on fiscal discipline. Indications of such concerns can also be gauged from the Ninth Plan document where the union government's policy regarding the funding of SRTUs is outlined. The thrust of the policy is to fund the acquisition 
of buses for replacement only, and not for fleet expansion. Public bus fleet expansion is to be funded from the private sector. In fact, the Ninth Plan document also states that, given the financial constraints facing the SRTUs, 75 percent of the public transport services should be made available from the private sector (Planning Commission 1999). Thus, it would be difficult for the state government to perpetually finance public transport losses, let alone make a capital contribution for fleet augmentation.

Activities that can be performed by several operators (i.e., those on which scarce public funds need not be spent) should be separated from those best performed by a monopolistic service provider. Thus, public funds would be used only for those activities in which private funds are either not available or public funding and management is desired. Such a separation of activities would also open up other opportunities for revenue generation (e.g., commercial exploitation of land resources).

\section{Comparative Advantage of SRTUS}

Some SRTU functions, such as the workshop activities, are not natural monopolies based on economies of scale and are currently being provided by a number of private sector operators. It may be difficult to justify continued public expenditure on such activities, especially if these services can be provided more efficiently by the private sector. Charles Lave uses this idea as the foundation for his argument that policy making should be separated from operating functions. He sees the role of the government authority as arranging or sponsoring public transportation rather than supplying the transportation itself (Urban Transit 1975).

A review of the current market structure in the urban public transport sector also reveals that SRTUs do not have a comparative advantage ${ }^{2}$ in a number of activities they are undertaking. This is particularly true for bus operations where private operators provide these services in a more cost-effective manner (though given the universal service obligations in the sector, private operations would have to be appropriately regulated). Similarly, the SRTUs do not have any comparative advantage in operating workshop facilities, which are competitively provided by the private sector for all types of vehicles.

\section{International Experience in Reforming Public Transport}

The situation of existing public transport institutions being grossly inadequate to provide required levels of service to effectively deal with the rapidly increasing congestion and pollution is not peculiar to India alone. It has been faced in most major 
cities around the world. Several of them have undertaken reforms and restructured their public transport operations to meet the required demand and the expected quality of service.

An examination of the reforms carried out around the world reveals two main trends in the restructuring of public transport. The first is to unbundle the monolithic and integrated services into more manageable and compact constituent units. This has generally resulted in greater involvement of the private sector in providing services in a competitive environment. The second trend is to segregate policy and planning from operational functions. This enables a separation of activities that are natural monopolies from activities that are not natural monopolies. Such separation makes it possible to bring in competition in activities that are not natural monopolies. Competition, in turn, enables improvements in efficiency, enhancement of capacity by tapping private financial resources, and induction of more professional management. In addition, it becomes possible to channel scarce public funds into activities the public sector is best suited to perform and not use them in activities that the private sector is better equipped to perform.

\section{Models of Private Sector Involvement}

Private sector participation can take different forms in infrastructure sectors. The public transport sector, in particular, can either be unbundled and opened in a segmented fashion to private sector participation, or the complete sector can be opened to such processes. These options are discussed below.

Service Contracts. This is a type of short-duration contract in which a private operator performs specific tasks such as provision of buses. By using this option, it is possible to take advantage of private sector expertise in performing technical tasks, or even to open such tasks to competition. Under this option, the public utility manager coordinates the tasks performed by private operators and ensures the investment in the sector. It is not possible to bring management expertise or improve operating efficiency in this option. However, unlike other infrastructure sectors, it is possible to bring additional investment under this option in the public transport sector as discussed below.

The most common form of the service contract in the public transport sector is the gross cost model for private sector participation in bus operations. This requires the government authority to set the routes operated and fares to be charged. Fare revenue accrues to the government authority, which then pays the private operator an agreed amount, irrespective of the occupancy and 
ridership. The operator is simply a supplier of a service, bearing the operating risks but insulated from revenue and ridership risks. This way each route can be operated by multiple private operators and the private operators do not have any incentive to recklessly race each other to each bus stop to gain more passengers. Furthermore, private operators are not hurt by fares that do not correspond to costs. Hence, this approach is suitable in cases where fare revenues are likely to be uncertain (e.g., new routes, low-density corridors, and in cases where government wants to subsidize commuters).

The quality actually achieved needs to be monitored by a public entity with a system of penalties to deter underperformance. The government authority awards routes via competitive tender to the lowest bidder. Preference is given to private operators who have achieved high standards of quality. This prevents private operators from concentrating only on dense routes and provides them with the incentive to improve quality.

The terms of the gross cost approach are somewhat similar to that of the kilometer scheme except that in the kilometer scheme payments are fixed regardless of the type of route or the time of day. In the gross cost scheme, the operator bids for the compensation. Such a bidding process permits an operator to factor the type of route and service quality expected into the amount being bid for as compensation.

Management Contract. This short-term option transfers the responsibility for the operation and maintenance of the system to a private operator for a fixed fee. This fee could be related to various performance parameters. Although the public utility is still responsible for rehabilitation and new investment, this option could bring technical and management expertise to the sector and, to some extent, improve operating efficiency. Management contracts in the transport sector are particularly relevant in the management of depots and workshops of large bus operators.

Lease Contract. Under this option, a private firm leases assets of the public utility typically for $\mathbf{1 0}$ to $\mathbf{2 0}$ years for a fee and takes on the responsibility for operating and maintaining them without any responsibility of financing new investment, which will lie with the public utility. This contract could bring technical expertise, managerial expertise, and operating efficiency to the sector. While investment risk lies with the public utility, the commercial risk is shared 
between the private operator and the public utility. This form of private participation is seldom seen in the public transport sector. Nevertheless, it is possible to develop lease contracts in the transport sector for some activities (e.g., depots and terminals).

Concession Contract. A concession agreement, or franchise, is a means of awarding fixed, long-term monopoly rights to provide a service to a private firm within a geographical area. Under this option, the private operator is not only responsible for operation and maintenance of existing assets but also for new investments, although the ownership lies with the government or the public utility. This option could bring technical expertise, managerial expertise, operating efficiency, and additional investment to the sector. Investment risks and commercial risks lie with the private operator.

The application of the concession type of private participation in the public transport sector is the net cost scheme in the public transport sector, whereby the operator receives the revenue from ticket sales, as opposed to a fixed payment in the gross cost approach, thus taking the risk of changes in financial performance over the contract period. A public entity continues to set routes, prescribe fares and service quality, and may either provide a fixed subsidy or receive a fixed contract fee (if the route makes profits). The government authority awards each route via competitive bid to the private operator requiring the least amount of subsidy or willing to pay the greatest fee.

Due to the revenue risk, this option would be suitable for high-density corridors with only a few operators, where ridership would be more certain, so that private operators have no motivation to adopt dangerous passenger capture techniques (e.g., rash driving and speeding). However, this would imply that a private operator would have a near monopoly over an area and would require appropriate regulation to ensure that such monopoly power is not misused.

Divestiture. This option, achieved through the sale of assets or shares or through management buyout, can be partial or complete. It gives the private operator full responsibility for operation, management, and investment. Unlike the concession contract, it transfers ownership of assets to the private sector. This is the model that has been adopted in the rail transport industry in the United Kingdom. 


\section{Lessons for Restructuring Public Transport}

The two relevant options for bus operations highlighted above are the gross cost and net cost options. In deciding between the two, a key concern is whether large private operators would come into the sector in India. If not, then the net cost option will not solve the safety problem. The gross cost option is also favorable because under this plan it is easier to integrate fares among different operators and different modes (Walters 1998). Finally, if the government perceives the need to subsidize commuters, the gross cost option would shield private operators from such revenue risks. However, the gross cost option requires more monitoring because the private operator will have no incentive to attract passengers or accurately collect fares. If the government authority cannot provide the required monitoring, then the use of the gross cost option will result in decreased quality, falling ridership, and increased costs to the government authority.

Given the lack of proven capacity of the private sector to operate large public transport fleets in urban India, the gross cost option may be a more feasible option in the short run to initiate private participation in public transport. Also, this option would allow the government to gradually phase out subsidies so as to minimize political and community resistance to restructuring. Over time, operations under the kilometer scheme would allow the private sector to develop its capability to operate and manage large public bus fleets.

\section{Unbundling State Bus Operators}

Urban SRTUs provide public transport services in India using both their own fleets and by leasing buses from private operators under the kilometer scheme. In addition to operating these bus services, SRTUs also repair and maintain the vehicles. The repairs and maintenance wing provides technical support to the SRTU buses only and not to private bus operators despite having excess staff in this category, as is the case with Delhi Transport Corporation (DTC) (DTC 2001). Thus, there exists a resource of technically competent personnel, which can be used to service additional vehicles. The SRTUs also own land for parking buses (at depots) and passenger terminals for providing traffic interchanges. ${ }^{3}$ 
These activities are representative of most urban SRTUs in India. It is possible to classify the activities of urban SRTUs as:

- operating buses;

- providing parking facilities for buses, terminal facilities for passenger interchanges, and bus stations; and

- carrying out repairs and maintenance.

These three activities, though independent of each other in the sense of requiring an independent operational structure and separate staff, do not function as separate profit centers. No separate accounts are maintained to evaluate which of these is a profitable activity. Ideally, these three activities should be operated as discrete profit centers.

\section{City Bus Operations}

Operating city services is clearly not a natural monopoly because several private operators are already operating services on city roads. An international review reveals that with appropriate regulation, private operations of public bus services would be successful. In light of the precarious financial position of the Indian government and the continuing losses suffered by the SRTUs as well as the feasibility of bus services being provided in a competitive market, greater involvement of the private sector in operating services in urban areas is recommended. The government should largely concern itself with policy making, planning, coordination, and regulation, rather than with actual operation of services.

India's experience with private operation of public transport has not always been a success. Assessments of privately operated buses in Delhi reveal poor quality of service delivered and low level of commuter satisfaction (Goel 2000). However, through private sector participation, such as in the kilometer scheme in both Delhi and Bangalore, the SRTU has increased its market share without any additional capital expenditure (DTC 2001). In using hired buses, the SRTU would save on capital investments, thus reducing the strain on the exchequer. However, it will be saddled with problems associated with the current form of the kilometer scheme, namely, the unwillingness of operators to operate on crowded routes and during peak hours or their motivation to make compromises on ridership. On the other hand, in allowing only private operators under concession contracts, the public transport system would remain uncoordinated and also run the risk of dangerous driving practices being adopted by operators. 
It is recommended that SRTUs not augment their urban bus fleet. The additional ridership demand should be met by obtaining services from private operators on gross cost contracts. Over time the SRTUs should phase out their own bus services by not replenishing the fleet and substituting their services with contracted services. To avoid the pitfalls associated with the kilometer scheme, the compensation payable should vary from route to route and also by time of day. An effective monitoring system needs to be in place to ensure that there is adherence to the contractual terms.

Over time the private sector operations would mature and the government could withdraw from operation of public buses completely and only regulate the sector. Such a gradual process would also allow the SRTUs to recover their investments in the public transport sector completely. Also, public bus operations for an initial period in competition with the private sector would enable a regulatory agency to set benchmarks for quality and also allow time for experience to be gained with net cost contracts before public operation is completely stopped. A gradual process would also help build support for such reforms. Finally, a gradual rationalization of the tariff regime would ensure financial viability of the sector and it would be feasible to transfer the revenue risk to the private sector.

Apart from restructuring the SRTU operations, another area of concern in the public transport sector is the operation of individual services. Clearly, such operations would not fit into the new scheme. However, it would be legally difficult to terminate these services, as they are operating under valid permits. Nevertheless, recourse could be taken to the provisions of section 103 (2) of the Motor Vehicles Act of 1988, which permits the state government to cancel an existing permit or modify the terms of an existing permit. However, there may be a disruption in public transport services if these operators do not join the kilometer scheme immediately. Another alternative would be for the operators to form large cooperatives, which would be given operating contracts. These permits could be allowed to lapse and not be renewed. This alternative would permit a gradual withdrawal of private individual bus services. Hence, it is recommended that existing permits be canceled and brought under the ambit of gross cost contracts.

\section{Depot and Terminals}

Ownership and management of depots, terminals, and bus stations are a natural monopoly, and it would be inefficient for a multiplicity of operators to own and manage these infrastructure facilities. These properties should be provided as common facilities for all operators. Nevertheless, the activities can be still operated as a 
separate profit centers in the form of a separate corporation. Due to the monopoly nature of the activities, it is recommended that the state government retain a controlling stake in the corporation, thus effecting partial divestiture. Another alternative would be to allow professional management of these properties by the private sector using lease contracts. In either case, unbundling these activities from bus operations by setting up a separate corporation would facilitate the lease contracts.

The corporation should enter into contracts with the intercity bus corporations and the SRTU or any private operators to allow parking within its premises for an appropriate fee. Also, the company could earn substantial revenues through property development and advertising. It could lease space for suitable retail outlets for additional revenues. This would have the twin benefits of revenue generation as well as improving access to public transport. As the SRTU lacks professional expertise to develop or manage commercial property, it is suggested that separate Special Purpose Vehicles (SPVs) be considered for each property as a joint venture with a strategic partner such as a reputed property developer company so that the requisite property development and management skills are available.

It is important to recognize that commercial development of the properties allocated to this company could be more remunerative than provision of parking facilities for buses or interchanges for passengers. Thus, if the company is to operate on commercial considerations only, there might be a conflict in the provisioning of such services and operating only on profit considerations. While it is recommend that the company operate only on commercial considerations, for commercial development of its properties it would need approval from appropriate regulatory agencies.

\section{Repairs and Maintenance Workshops}

Management of the workshops and repair facilities is not a natural monopoly. There are several private workshops at which repairs could be carried out and there is no need for public funds to be spent on these facilities. However, given the fact that substantial infrastructure for repairs already exists with SRTUs, they may be used for repairs and maintenance of all buses and other motor vehicles. The second advantage is that SRTUs also have technically competent personnel who can service the city vehicle fleet. However, repairs should be done on a purely commercial basis by charging market-based fees. If this activity can not be sustained in the 
public sector, then it should be privatized. A separate company should be used to facilitate this operation.

\section{Other Issues to be Resolved}

Restructuring SRTUs would help improve their financial performance and conserve public funds. Using the private sector to provide bus services would result in improved performance and additional capacity. Yet, the restructuring of SRTUs alone would not be sufficient for bringing about a marked improvement in the quality of public transport. To bring about the required improvements and attract private investments in public transport, it is necessary that several planning, licensing, and monitoring functions be performed effectively. These functions include:

- fixation of fares and fees;

- route and network design;

- route allocation and issue of permits;

- specification, monitoring, and enforcement of quality of service standards;

- coordination;

- data collection and management;

- dispute resolution; and

- making recommendations to government on policy matters. 


\section{Endnotes}

1. The area outside the city is called "mofussil."

2. This means a firm is more competitive in the delivery of that service.

3. Interestingly, while the privately operated public buses (Blueline buses) in Delhi are permitted to use the terminal facilities for picking up passengers, for which they pay a charge of Rs 2,500 per month for using the bus stands and Rs 5,000 per month for using terminals, there is no provision to let them use the depot facilities for parking. DTC collected nearly 20 million rupees in 2000-01 for such charges. 


\section{References}

ASRTU (Association of State Road Transport Undertakings). 2000. State transport undertakings: profile and performance 1998/99. New Delhi.

Delhi Transport Corporation. 2001. Operational statistics. October 2001.

New Delhi: Delhi Transport Corporation.

Goel, T. 2000. Urban bus transit system in Delhi-An assessment of the quality of service. Indian Journal of Transport Management (May).

Ministry of Surface Transport (MOST). 1999. Motor transport statistics of India 1997. New Delhi.

Planning Commission. 1999. Ninth five-year plan (1997-2002). New Delhi.

Urban transit: The private challenge to public transportation. 1975. Charles A. Lave, ed. San Francisco: Pacific Institute for Public Policy Research.

Walters, J. 1998. The role of institutional structures at metropolitan level in SA in organising public bus transport. In Urban transport policy: A sustainable development tool. Peter Freeman and Christian Jamet, eds., Rotterdam: Balkema.

\section{About the Author}

KAUSHIK DEB (kdeb@teri.res.in) is a research associate in the Policy Analysis Division of the Tata Energy Research Institute, India. He is also the area convenor of urban and transport systems area in TERI. Mr. Deb has a master's degree in economics from the Delhi School of Economics at the Delhi University. His current areas of research include urban transport and environment, with special focus on reforms in public transport. 